\title{
Improving Service Quality in Our Classrooms: Student Feedback as a Quality Mechanism for Teaching
}

\author{
Jhalukpreya Surujlal \\ North-West University (Vaal Triangle Campus) \\ Email: Babs.Surujlal@nwu.ac.za
}

Doi:10.5901/mjss.2014.v5n13p191

\begin{abstract}
Academic staff in higher education receive feedback from the top where superiors appraise them, horizontally where peers appraise them and, to a lesser extent, from the bottom where students appraise them. This feedback impacts on the quality of service that academic staff provides and ultimately the image of the institution. If academics consider their students to be their 'customers' then who better than students can provide information regarding the quality of service that they provide. To date most of the literature on feedback has focused on lecturers providing feedback to students. Limited research has focussed on student feedback although ample anecdotal evidence exists suggesting that student feedback does contribute to improved teaching approaches by academics and a better understanding of student needs. The current study was designed to highlight and understand student feedback through the reflections and experiences of academic staff in two universities in the Gauteng province of South Africa. A qualitative research approach was used to access information on the perceptions of a purposive sample $(n=12)$ of academics of student feedback as a measure of their quality of teaching. The following themes emerged through the analysis of the data: quality, frequency, process, constraints and reliability, benefits and timing. The results indicate that academics found student feedback to be a valuable indicator of the quality of their teaching and the curriculum. Recommendations arising from the findings were provided for academics.
\end{abstract}

Keywords: Student feedback, service quality, academics, teaching, curriculum

\section{Introduction}

Academic staff at Institutions of Higher Education receive feedback regarding their performance in various ways. These include receiving feedback from the top where superiors appraise them, horizontally where peers appraise them and, to a lesser extent, from the bottom where students appraise them. This feedback impacts on the quality of service that they provide and ultimately the image of the institution. Bailey (2008) suggests that feedback can be construed as both a teaching and learning process.

Currently, service quality is a focus for many corporate and marketing strategies. This focus could also be shifted to Institutions of Higher Education where high levels of service by academics can create value-laden relationships with students thereby creating opportunities for their institutions to achieve a competitive advantage and differentiation. Education has a high personal interaction component resulting in varying degrees of service delivery among different academics. Students could play a pivotal role in improving the delivery of this service.

If academics consider their students to be their 'customers' then who better than students can provide information regarding the quality of service that they provide. From this perspective if customer expectation (learner expectation) of service quality is not met, a mutually satisfying relationship between the academic and the learner is hardly possible. There are various methods to obtain student feedback. While questionnaires have been regarded as the most popular method of obtaining student feedback, other methods of obtaining student feedback include student representation of staff committees, structured focus group discussions, one to one interviews, electronic feedback, suggestion boxes, student diaries or logbooks and bulletin boards - depending on the purpose and context of the feedback (Keane \& Labrainn, 2005).

The quality of service that academics provide thus crucially determines learner satisfaction and learner retention. More often than not students are too shy or intimidated to ask questions in class, or to tell an academic personally that he/she is not coping with the teaching and learning done in the classroom. Student feedback gives students the opportunity to provide feedback to the lecturer about his/her teaching collectively and in a structured manner without being embarrassed. Student feedback can be administered informally without exerting pressure on either the lecturer or learner.

There are many factors which need to be taken into account regarding the gathering of student feedback. These include the timing of feedback, the types of feedback and the interpretation of feedback. 


\section{Benefits of Student Feedback}

The benefits of student feedback to academic staff are numerous. These include being aware of how one contributes to the success of one's students, enabling clearer communication that makes the academic aware of students' expectations, creating opportunities for new ideas and improved teaching methods and making one aware of how to improve or develop to attain greater levels of performance. By exposing unrealized potential it can take an academic to greater heights. The benefits also include getting to know student expectations, obtaining information of students' thoughts regarding their lecturer and identify areas for improvement.

Student feedback also provides the opportunity for students to rate teaching effectiveness. The information contained in the feedback provides useful insights regarding strengths and weaknesses as perceived by students. In many institutions student feedback on teaching and curriculum forms an important component of the process for quality improvement, quality assurance, and reward and recognition of teaching quality. It provides for collaborative (lecturer and student) critical reflection on teaching and curriculum so that areas of effective practice are identified and opportunities for improvement and development are presented (Academic Senate Macquarie University, 2010).

It is important to note that student feedback, at most times, are multi-dimensional, reliable, valid and uncontaminated (Marsh, 1987). Hendry, Lyon and Henderson-Smart (2007) commented that valuable comments from student feedback helps to improve teaching. Gibbs and Simpson (2004), on the other hand, are of the view that feedback from students potentially helps one to distinguish between the best curriculum and the worst curriculum. Good feedback provides the opportunity for lecturers to close the gap between student expectations and lecturer contribution. It provides rich information to lecturers regarding the quality of their teaching and creates the opportunity for dialogue around teaching and learning. It provides indicators to lecturers on how they can shape the learning experience in class (Di Costa, 2010).

Student feedback on the ambience in the classroom can prove to be very valuable in improving the quality of students' experience of the lesson. In the marketing literature ambience is referred to as atmospherics which is a concept used to define and interpret attributes of a service setting (Milliman \& Fugate, 1993). In the context of this study the service setting is the lecture room in which the style, appearance, temperature, sound and smell are 'consumed' by students. Because of students' interaction with the various aspects of the atmospherics in the lecture room, it is important for lecturers to know what appeals to students as they will invariably influence their attendance, concentration and receptiveness. Research (Donovan, Rossitter, Marcoolyn \& Nesdale, 1994) supports the idea that the environment influences the attitude and behaviour of students (consumers).

In a broader context student feedback may provide deans and departments with information on teaching effectiveness. This can be used to make informed decisions regarding retention, promotion and incentives.

\section{Barriers to Feedback}

Academic staff at higher education institutions often experience high workloads. They are required to finish their syllabi within the recommended period as well as intervene if student performance is poor. As a result academic staff face time constraints to organise feedback sessions. If a feedback session is indeed organised, it may be rushed and may make little meaningful contribution for the lecturer.

Depending on the type of feedback that is required, large class sizes may hinder a lecturer's attempt to get feedback from students. Not only will the process to get feedback be time consuming, the capturing of the responses, analysis and interpretation of the feedback may also be time consuming.

The level of difficulty of the syllabus as well as the content of the syllabus may influence the type and quality of feedback a lecturer receives. While lecturers are viewed by students as transmitters of knowledge, their inability to cope with the demands of the syllabus may manifest itself in inaccurate feedback which will have little value in improving service quality. Sometimes students tend to base their feedback on the popularity of the lecturer rather than on the lesson and this may affect the objectivity of their feedback (Richardson, 2005; Bhattacharyya, 2004).

While students may be able to provide feedback on a number of issues such as presentation, style, classroom ambience and use of technology, Richardson (2005) argues that in some instances students are not competent enough to make judgements on teaching.

\section{Service Quality in the Classroom}

The Customer Satisfaction theory (Klaus, 1985) regards service quality as a perception of quality: a service is only of the 
desired standard if the customer sees it as quality. Within this theory, service quality is defined as the difference between expected service and actual service received. Delivering quality service means conforming to customer expectations consistently. Placing this understanding in the context of the classroom one may suppose that the student would view the 'service' delivered by a lecturer of a desired standard if s/he was satisfied with it. It is therefore important for lecturers to be aware and informed of the service they deliver. Similar to opinion surveys which service providers conduct to get information regarding the services they provide, lecturers can use student feedback to get information on the quality of the lessons they deliver.

During student feedback information on the following components, among others, of the learning experience may be obtained: presentation of the lesson, lesson content, appearance, behaviour and mannerism of the lecturer, timing of the lecture, handling of queries, efficient use of lecture time, use of technology, blend of different methodologies and level of understanding. While in many instances the layout of a classroom is beyond the control of the lecturer, attempts to make the classroom as conducive as possible also form part of the feedback by students. An appropriate and carefully balanced mix of these components may lead to enhanced service quality in the classroom. In some instances the 'service encounter' may extend beyond the boundary of the classroom. This may involve how accessible the lecturer is to the student after the lesson for consultation.

It is important to realise that service quality is a highly subjective concept and there are many factors, both internal and external, which may influence one's perception of service quality (Sivadas \& Baker, 2000). A service is generally perceived in a subjective fashion. Grönroos (2007: 54) posits that services are usually described by customers as an 'experience', 'trust', 'feeling' and 'security'. In the context of teaching the trust and feeling of security which students experience in the lecture room plays an important role in how they experience the lesson. Similar to other services such as customer service and sport coaching, service quality in the context of teaching is abstract and elusive to measure and understand. The unique features of services, such as inseparability of production and consumption, intangibility, and heterogeneity, make the measurement of service quality in the classroom a complex task. In the absence of clear objective means to measure service quality, this study views the feedback from students regarding their perception of the quality of their lecturers' teaching as a measure of service quality.

\section{Problem Statement}

Bailey (2008) comments that in the climate of change and reform in higher education an important intervention has been attempt to standardise and systematise the teaching and learning context by introducing quality assurance measures in the shape of structured feedback. A 360 degree feedback process regarding the evaluation of the curriculum, methods of delivering lessons and the competence and ability of a lecturer to deliver a lesson has virtually become standard practice in higher education (Kember \& Leung, 2009). Tinto (1987) postulated that integrating students into the different aspects of university life plays an important role in the learning process.

Systems for evaluating teaching quality have long been established and are common practice in higher education (Hoyt \& Perera, 2000). While there exist views that students may not be competent enough to make judgements on teaching and course quality, Coughlan (2004) argues that only students are in a position to provide feedback on the quality of the delivery of lessons.

Although there is a substantial body of evidence regarding the profound effect of teaching method, learning tasks and assessment methods on student learning (Kember \& Gow, 1994), there is a dearth of scholarly research on the relationship between student feedback and service quality. To date most of the literature on feedback has focused on lecturers providing feedback to students. While there is also ample anecdotal evidence that student feedback does contribute to improved teaching approaches by academics as well as a better understanding of student needs and students in general, it is surprising that limited research has been done on student feedback. This study aims to fill the research gap and add to the knowledge base of student feedback.

\section{Purpose of the Study}

The current study is designed to highlight and understand student feedback through the reflections and experiences of lecturers in two universities in the Gauteng province of South Africa.

\section{Method and Procedures}

A comprehensive literature study was conducted on student feedback and service quality. In addition, a qualitative and 
exploratory approach was used to access information on the perceptions of a purposive sample $(n=12)$ of lecturers of student feedback as a measure of their quality of teaching. Purposive sampling allows the researcher to access critical and rich information from participants who have firsthand knowledge of the phenomenon being researched (Patton, 2002). Participants were selected on the following basis: a) they were academics who obtained feedback from their students regarding their teaching; b) they had at least 5 years teaching experience in tertiary institutions; and c) their willingness to participate in the study.

The author deemed that by using this approach, the use of semi-structured questions and probing during in depth interviews would give participants the opportunity to respond in their own words, rather than forcing them to choose from fixed responses that are required in a quantitative approach. This approach also has the ability to evoke responses that are meaningful and applicable to the respondent, unforeseen by the researcher, rich and explanatory in nature.

\subsection{Interview schedule and procedure}

According to Côté, Salmela, Baria \& Russell (1993) the interview schedule is the most widely used framework for qualitative research. In this study a semi-structured interview format was selected as the most appropriate means of obtaining rich and diverse information on student feedback. The content and the design of the interview schedule were developed based on relevant literature on student feedback and methodological sources on qualitative interviewing (Denzin \& Lincoln, 2000; Patton, 2002). A pre-test of the interview schedule by two experienced researchers as well as three lecturers was first conducted to determine the clarity of the interview questions, the approximate duration of the interview, and to obtain feedback on how the interview schedule could be improved. The feedback received necessitated a few changes to the interview schedule.

Prior to the interviews, the researcher identified and contacted potential participants, explained the purpose of the study and requested them to participate in the study. Appointments were made with twelve participants who gave their consent to participate in the study. Most of the interviews took place at the participants' university.

A standardized format through which each participant was asked the same questions in the same way was used for the interview schedule. Follow-up probes were also utilized in order to elaborate and clarify some responses. The sequence of the questions was not strictly followed and varied according to the flow of the conversation. Thus, while the interview was structured and standardized, there was flexibility in interviewing the participants and the way they presented their experiences of student feedback. This allowed greater depth of information as well as the building of rapport. The interviews were recorded with the permission of the respondents. As a back-up notes were taken discreetly during the interview. It was noted that data saturation - a point where no new data emerged (Henning, Van Rensburg \& Smit, 2004) - was reached at the $8^{\text {th }}$ interview. It was therefore not necessary to conduct the remaining interviews.

\subsection{Ethical considerations}

At the outset all participants were informed that participation was voluntary, their responses would be confidential and that they would remain anonymous at all times.

\subsection{Data analysis}

Qualitative content analysis was conducted on the data. According to Downe-Wamboldt (1992: 314) the goal of content analysis is "to provide knowledge and understanding of the phenomenon under study". The process involved referring to the notes, listening to the recordings and transcribing recurring words and ideas which were then clustered into categories. Following this thematic labels were then attached to the categories. Thereafter the researcher listened to the recordings in conjunction with the transcripts again to ensure that all relevant information was captured.

\subsection{Trustworthiness}

The researchers who assisted in the pre-testing of the interview schedule were requested to test the validity of the themes which emerged through the content analysis of the data. Both the recordings as well as the transcripts were sent to the researchers who examined the findings independently. This was done by examining the appropriateness of the identified themes in conjunction with the transcripts and audio recordings. Once this was done the three researchers came together to discuss the findings until consensus was reached regarding the themes. In addition, two participants were randomly chosen to check the content and the quality of the transcripts of their interview. Their feedback indicted that the data were captured accurately. 


\section{Results}

The following themes emerged through the analysis of the data: quality, frequency, process (content and instrument), constraints and reliability, benefits and timing. The themes, operational definitions and narratives associated with the themes are provided in Table 1.

Table 1: Themes, Operational definitions and Narratives

\begin{tabular}{|c|c|c|}
\hline Theme & Operational definition & Narratives \\
\hline Quality & $\begin{array}{l}\text { This refers to student feedback meeting the needs } \\
\text { and expectations of lecturer }\end{array}$ & $\begin{array}{l}\text { "questions are too general" } \\
\text { "there must be more focussed questions" }\end{array}$ \\
\hline Frequency & $\begin{array}{l}\text { This refers to the number of times per semester/year } \\
\text { that student feedback should be conducted }\end{array}$ & $\begin{array}{l}\text { "one session per year is too few" } \\
\text { "should be more than once per semester" }\end{array}$ \\
\hline Process & $\begin{array}{l}\text { This refers to the steps in the feedback process. It } \\
\text { includes content, collection, analysis and } \\
\text { interpretation of the results }\end{array}$ & $\begin{array}{l}\text { "the way in which feedback is done should be reviewed" } \\
\text { "I prefer to do feedback my way" }\end{array}$ \\
\hline $\begin{array}{l}\text { Constraints and } \\
\text { Reliability }\end{array}$ & $\begin{array}{l}\text { This refers to the restricting or limiting factors } \\
\text { associated with student feedback }\end{array}$ & $\begin{array}{l}\text { "relationship with students affect how lecturers are rated" } \\
\text { "some student are not competent enough to give feedback" } \\
\text { "I do not believe students are honest" }\end{array}$ \\
\hline Benefits & $\begin{array}{l}\text { This relates to the positive outcomes of student } \\
\text { feedback. It includes both personal development and } \\
\text { development of lessons }\end{array}$ & $\begin{array}{l}\text { "some of my areas of weakness I was not aware of were } \\
\text { discovered" } \\
\text { "I knew where to focus more attention in the syllabus" }\end{array}$ \\
\hline Timing & $\begin{array}{l}\text { This refers to the selection of the best moment for } \\
\text { conducting student feedback from which maximum } \\
\text { benefit is derived }\end{array}$ & $\begin{array}{l}\text { "the timing of the feedback is problematic" } \\
\text { "too late in the year" }\end{array}$ \\
\hline
\end{tabular}

\section{Discussion}

\subsection{Quality}

The findings of the study resonate strongly with the wider literature on student feedback. With regard to the quality of feedback this theme was divided into sub-themes, namely content, expectations and worth. Respondents indicated that the content of the questionnaires required feedback on too many aspects and were too general. They were thus of the opinion that this compromised the depth of the feedback. This was because most respondents were not in a position to change the system as this was done by a different department. Respondents preferred that feedback on specific aspects should be requested at respective feedback sessions e.g. student effort and involvement, communication, lesson organisation, preparation and presentation, lesson content, assessment, assignments and student presentations. This finding is in agreement with Keane and Labrainn (2005) who suggested that with regard to the content of the feedback, it should be direct and course-related rather than focussing on a range of activities. In most instances the feedback did meet the expectations of the respondents. Furthermore all respondents indicated that there were developmental opportunities associated with the feedback.

\subsection{Frequency}

With regard to frequency respondents perceived that the frequency of feedback sessions was insufficient. They felt that more frequent and shorter feedback sessions would most probably be more beneficial to them as well as the students. All respondents indicated that student feedback which was organised by other departments was conducted at the end of the semester or academic year. In many instances they lamented the fact that they could not implement the findings with the same group of students either because the students were allocated to another lecturer in the following year or the syllabus was completed. Most respondents indicated that they would prefer student feedback to be conducted in the middle of the semester so that they could implement the findings. This finding mirror those of Narasimhan (2001) who argued that feedback obtained at the end of a syllabus would have little or no value compared to that which is received in the middle of the syllabus. 


\subsection{Process}

Respondents were unanimous that the current method of feedback should be reviewed. Currently the feedback was conducted by a different department who had a different mandate and objectives. In this regard Hounsell (2003) suggested that the first step in the student feedback process should be to define the objective of the feedback. This would then provide direction regarding the development of the instrument or choice of the appropriate instrument to get feedback. The perceptions of the respondents regarding the purpose of student feedback corroborated those of Keane and Labrainn (2005) who suggested that the process of feedback in higher education gives the impression that it is being done to fulfil an administrative obligation. In keeping with the objectives for feedback, respondents suggested that the content of the instrument should be relevant. They also preferred to conduct their own feedback.

\subsection{Constraints and Reliability}

One of the constraints experienced by the respondents was that they were not able to use their own method of student feedback. This was because approved standardised instruments administered by staff from other departments were used. Richardson (2005) expressed the concern that in the classroom the students are 'forced' to participate in the process which is supposed to be voluntary. This compromised the quality of the feedback. In some instances the performance of the students in a particular module/subject influenced their feedback. If students performed well they were likely to rate the quality of the lesson higher than those in which subjects they performed poorly. This finding is in sync with those of Worthington (2002) who found that where students expected to perform better, the student feedback of the lecturer was higher. Most of the respondents indicated that large class sizes and long syllabi limited their opportunity to request feedback from the students. They therefore used one-on-one consultations or short informal feedback sessions towards the end of their lesson instead.

\subsection{Benefits}

All respondents in the study perceived feedback to be beneficial. It provided them with information to reflect on their strengths and weaknesses as well as identify areas for improvement in the syllabus. This finding is in line with Scott and Issa (2006) who found that student feedback can be a powerful source for an instructor's professional development. Participants in the study used student feedback to adapt their lecturing style, select appropriate technology for their lessons, structure the pace of their lessons and identify areas of the syllabus which students experienced difficulty in understanding. Three of the respondents who found student feedback valuable developed their own feedback questionnaire which they administered from time to time to the different groups they lectured to. Using the feedback they adapted their lecturing style to enable greater involvement of students in the lesson.

\subsection{Timing}

Respondents expressed their concern regarding the timing of the feedback sessions. In most instances respondents felt that the feedback sessions were scheduled too close to the end of the academic year. Hence, those students who provided the feedback would not be in a position to enjoy the development and improvements based on their responses. This finding mirrors those of McKeachie and Kaplan (1996) who argued that feedback would be most informative if it were administered when as much of the course content as possible has been covered. Furthermore, respondents indicated that in most instances the feedback was administered during class time towards the end of a lecture. This caused students to rush over their responses without giving careful thought to their feedback.

\section{Limitations of the Study}

An important limitation of the study was the small sample size. Hence, the findings cannot be generalised to the larger population of lecturers. Notwithstanding this limitation the study provides noteworthy results and provides a base for future research on student feedback.

\section{Recommendations}

Emanating from the study were three strong recommendations from the respondents. Firstly, respondents recommended that student feedback questionnaires should be customised and purpose-driven, i.e. there should be specific outcomes 
attached to each session. Respondents were not comfortable with the idea of student feedback being used only for incentives and promotion. Secondly, respondents preferred feedback sessions to be scheduled during the period when a third to half the syllabus or semester was completed. This would then provide them with the opportunity to respond to the feedback with the same group of students and observe any changes. Thirdly, respondents indicated that they were keen to contribute to the development of the feedback questionnaire and the feedback process.

\section{Conclusion}

The aim of the study was to highlight and understand student feedback through the experiences of university lecturers. The study provided several interesting insights into how lecturers experienced student feedback. It is evident that student feedback provided them with excellent information not only for their own professional self-development but also to improve the curriculum and develop their lessons so that students get maximum benefit.

\section{References}

Academic Senate Macquarie University (2010). Student Feedback on Learning, Teaching and Curriculum Policy. Retrieved from: mq.edu.au/policy/docs/student_feedback/policy.pdf. 2014/03/21.

Bailey, R. (2008). Academic staff perceptions of the role and utility of written feedback on students' written work. Retrieved from http://www.zeitschrift-schreiben.eu/Beitraege/bailey_Academic_staff.pdf. 2014/03/17.

Bhattacharyya, N. (2004). Student evaluations and moral hazard. Journal of Academic Ethics, 2, 263-271.

Côté, J., Salmela, J.H., Baria, A. \& Russell, S. (1993). Organizing and interpreting unstructured qualitative data. The Sport Psychologist, 7, 127-137.

Coughlan, A. (2004). Evaluating the learning experience: the case for a student feedback System. Quality Promotion Office, National University of Ireland:Maynooth.

Denzin, N. K. \& Lincoln, Y. S. (Eds.) (2000a). Handbook of Qualitative Research (2nd ed.). Thousand Oaks, CA: Sage.

Di Costa, N. (2010). Feedback on feedback: Student and academic perceptions, expectations and practices within an undergraduate Pharmacy course. Retrieved from http://www.uts.edu.au/sites/defaultfiles/DiCosta.pdf. 2012/05/06.

Donovan, R.J., Rossitter, J.R., Marcoolyn, G. \& Nesdale, A. (1994). Store Atmosphere and Purchasing Behaviour. Journal of Retailing, 70(3), 283-294.

Downe-Wamboldt, B. (1992). Content analysis: Method, applications, and issues. Health Care for Women International, 13, 313-321.

Gibbs, G. \& Simpson, C. (2004). Conditions under which assessment supports students' learning. Learning and Teaching in Higher Education, 1, 3-31.

Grönroos, C. (2007). Internal marketing - theory and practice. In T.M. Bloch, G.D. Upah \& V.A. Zeithaml (eds.) Services Marketing in a Changing Environment (pp. 41-47). Chicago: American Marketing Association.

Hendry, G., Lyon, P. \& Henderson-Smart, C. (2007). Teachers' approaches to teaching and responses to student evaluation in a problem-based medical program. Assessment and Evaluation in Higher Education, 32(2), 143-144.

Henning, E., Van Rensburg, W. \& Smit, B. (2004). Finding Your Way in Qualitative Research. Pretoria: Van Schaik.

Hounsell, D. (2003). 'Student Feedback, Learning and Development'. In M Slowey and D. Watson, (eds.) Higher Education and the Life course (pp. 67-78). Buckingham: SRHE \& Open University Press.

Hoyt, D. \& Perera, S. (2000). Validity of the Idea student ratings of instruction system: An update. Idea Research Report 2, Center for Faculty Evaluation and Development, Kansas State University: Kansas.

Kember, D. \& Gow, L. (1994). Orientations to teaching and their effect on the quality of student learning. Journal of Higher Education, 65 (1), 58-74.

Keane, E. \& Labrainn, I.M. (2005). Obtaining student feedback on teaching \& course quality. Retrieved from http://www.nuigalway.ie/celt/documents/evaluation_ofteaching.pdf. Accessed on 2012/04/05.

Kember, D. \& Leung, D.Y.P. (2009). Development if a questionnaire for assessing students' perceptions of the teaching and learning environment and its use in quality assurance. Learning Environments Research, 12, 15-29.

Klaus, P.G. (1985). Quality epiphenomenon: The conceptual understanding of quality in face-to-face service encounters. In Czepiel, J., Solomon, M.R. \& Suprenant, C.F. (Eds.) The Service Encounter: Managing Employee-Customer interactions in service businesses (pp. 17-33). Lexington, Massachusettes: Lexington Books.

Marsh, H.W. (1987). Students' evaluations of university teaching: research findings, methodological issues, and directions for future research. International Journal of Educational Research, 11, 253-388.

McKeachie, W.J. \& Kaplan, M. (1996). Persistent problems in evaluating college teaching. AAHE Bulletin, pp. 5-8.

Milliman, R.E. \& Fugate, D.L. (1993). Atmospherics as emerging influence in the design of exchange environments. Journal of Marketing Management, (3), 18-26.

Narasimhan, K. (2001). Improving the climate of teaching sessions: the use of evaluations by students and instructors. Quality in Higher Education, 7, 179-190.

Patton, M.Q. (2002). Qualitative Evaluation and Research Methods (3rd ed). Newbury Park. CA: Sage.

Richardson, J.T.E. (2005). Students' perceptions of academic quality and approaches to studying in distance education. British 
Educational Research Journal, 31(1), 1-21.

Scott S. \& Issa, T. (2006). Lessons learned from using students' feedback to inform academic teaching. In the 15th Annual Teaching and Learning Forum: Experience in Learning. University of Western Australia.

Sivadas, E. \& Baker, J.L. (2000). An examination of the relationships between service quality, customer satisfaction and store loyalty. International Journal of Retail and Distribution Management, 28(2), 1-13.

Tinto, V. (1987). Leaving College. Chicago:University of Chicago Press.

Worthington, A. (2002). The impact of student perceptions and characteristics on teaching evaluations: a case study in finance education Assessment and Evaluation in Higher Education, 27(1), 49-64. 